\title{
RADIO FREQUENCY IDENTIFICATION (RFID) INTEGRATED WITH BUILDING INFORMATION MODEL (BIM) FOR OPEN-BUILDING LIFE CYCLE INFORMATION MANAGEMENT
}

\author{
Min-Yuan Cheng and Nai-Wen Chang \\ Department of Construction Engineering, National Taiwan University Science and Technology, Taipei, Taiwan \\ *Corresponding author (D9705103@mail.ntust.edu.tw)
}

\begin{abstract}
This research developed an integrated "radio frequency identification with building information model" (RFID-BIM) to manage life cycle information related to open-building projects. The modularized components of openbuilding, including structural support systems and infill systems (e.g., partitions, facilities and pipes), which permits repetitive assembly and disassembly. Contractors prefabricate standard modular components offsite prior to installation. RFID technology can facilitate the effective storage and retrieval of critical information needed by management at different project phases. BIM frames the construction components and materials database and allows visual simulation of the building model. This study generated several significant results, these included: 1) Development of a 3D time factorintegrated figure able to generate a 4D virtual reality model for construction progress simulation in the planning and design phase; 2) Using the developed model, it can be successful checking of construction interfaces and conflicts during the detailed design phase; and 3) Control and real-time monitoring of construction installation work during the construction phase. Building on the general concept of platform integration, this study applied data exchangeability and process automation technologies to initiate data exchange and collect information in order to significantly raise the efficiency of open building projects. In summary, RFID-BIM provides a platform upon which various participants can organize and share information on all building project phases.
\end{abstract}

Keywords: Open-building, Life Cycle, BIM, RFID, 4D

\section{INTRODUCTION}

The open-building approach enhances construction project flexibility and reduces the resource consumption and environmental impact of structures through highly adaptive processes and by enhancing the recovery and reusability of building elements. The concept of open-building was first promoted in the 1960s. Open-buildings generally comprise a support and infill system and employ modular components in construction that in principle allow interior / structural remodeling as well as physical relocation to address changing user needs. While the open-building approach provides greater flexibility to meet user demands, construction characteristics require more preparation time during the planning and design phases. Architects and construction firms face significant additional planning and management responsibilities early on in terms of arranging component and materials pre-fabrication, arranging transportation and installation schedules, and sequencing equipment and worker operations.

Radio frequency identification (RFID) is a generic term for technologies that use radio waves to identify persons or objects automatically. RFID tags are attached to targets and read by a reader scanner. Construction managers use RFID to track component positions, obtain data on components and materials, and improve management of open-building construction projects. RFID is an increasingly used IT application due to its ability to read and process identification data remotely [1]-[3]. Accordingly, RFID and 
its data acquisition ability may be a proper application technology applied to manage component data through the building life cycle.

Traditionally, the building life cycle is divided into the five phases of planning and design, manufacturing, construction, maintenance and demolition. Many documents and drawings are associated with the various phases of the building lifecycle. Therefore, the manager requires an integrated method to manage the outcome and the information from the behavior of construction work. This information, including requests for information (RFI)[4], schedules, submittals, rarely serves as a reliable database for future decision-making and would be more effective if incorporated into the Building Information Model (BIM).

The National Building Information Model Standard (NBIMS) defines BIM as "a digital representation of physical and functional characteristics of a facility and it serves as a shared knowledge resource for information about a facility forming a reliable basis for decisions during its life cycle from inception onward."[5] BIM is an excellent technology that makes essential data available for managers to retrieve and display in formats consistent with their needs.

This project presents a platform to implement practical data collection using RFID wireless transmission technology and develops an open-building information model that encompasses all building components and provides component geometry, spatial relationship, property and quantity data. The researchers developed an RFID-BIM to provide graphic and non-graphic data including shop drawings, specifications, schedules, submissions, change orders, and RFI for building life cycle information management.

\section{OPEN-BUILDING INFORMATION INTEGRATION USING RFID}

The three parts of open-building component data collection and information integration are:
(1) Layout and coding of the open-building component: In order to communicate uniform component data to various phases of building life cycle and facilitate management for automation construction, the main point of this objective proposes that the coding method of building framework for each component of open-building may be assigned a unique code using RFID technology. According to user demand and current coding method (Fig. 1), the major factors adopted for this coding method framework reflect the four factors of (a) Project ID, (b) Number of floors, (c) Component type, and (d) Order number. The coding framework model of component is shown in Fig. 2.

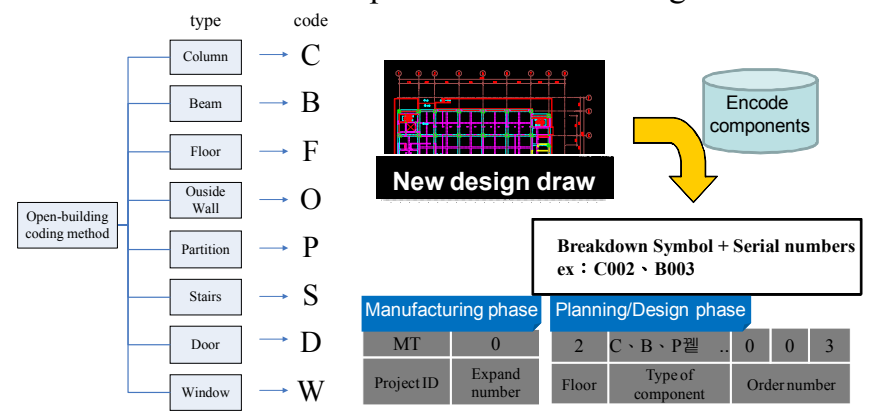

Fig. 1 Component coding method

Fig. 2 Encoding model for components

(2) RFID wireless transmission system: RFID wireless tran smission system uses technology that combines the inform ation identification system with radio frequency (RF) trans mission technology. Figure 3 shows the process of transmit ting data between the RFID Reader and Tag UID. It is appli ed to collect and transmit to the control center building co mponent data generated at the job site. RF has primary appl ications in areas where environmental constraints prohibit $\mathrm{t}$ he use of other automatic identification technologies [6, 7]. At construction sites, the location at which information $i$ s gathered and entered may change with construction sched ule progress. Construction sites are typically severe enviro nments that are typically stocked with a certain quantity of materials and components. RFID wireless transmission syst ems can dynamically transmit and receive information to $h$ elp identify objects even in the absence of "line-oflight." Information stored in the tag can be modified, which provides management flexibility. Thus, RF is an optimal $t$ 
echnology for gathering and transmitting data on constructi on materials and components.

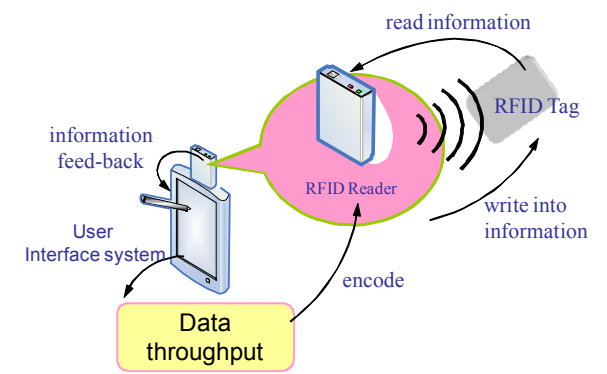

Fig. 3 Data transmission process: RFID Reader to Tag UID

(3) Automated data collection using RFID collector: Data collection efficiency is improved through the use of an automated RFID collector to gather and enter structural components information. There are two stages for using the wireless RFID transmission technology to collect prefabricated unit tag data: (a) job site entrance control management and (b) storage yard. A sensor collector at the site entrance reads prefabricated unit tags when units are transported onto the job site. Data is transmitted via wireless RFID to the control center and saved in the associated database. Prior to removal from the storage yard for use, unit information is read again and data is transmitted to the control center to check relevant installation information (e.g., position, sequence, component data, and materiel storage management, etc.). Figure 4 illustrates the framework RFID wireless transmission system model.

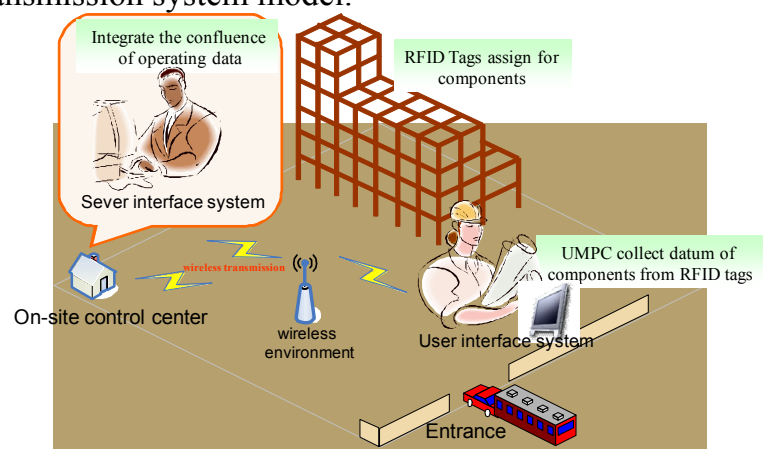

Fig. 4 Framework RFID wireless transmission system model

\section{IMPLEMENTATION OF BIM SIMULATION VIRTUAL REALITY MODEL AND DATABASE}

It is widely acknowledged that product modeling is the only solution for managing building information efficiently
[8]. A key benefit of BIM is its accurate geometrical representation of the three stages of building in an integrated data environment. This study considered the concept and technology and established a simulation model that includes:

(1) Integrating a 3D model with the open-building objects database: The BIM is a mature digital framework that models building components and their relationships. This study applied BIM technology to establish a 3D model able to imitate an actual open-building in the early phases of planning in order to inspect construction interfaces and reduce work conflicts. Component and materials data were then captured into the $3 \mathrm{D}$ model. BIM was employed to store construction documents including specifications, drawings, and requests for information. This project presents a practical approach to data collection that may be incorporated into a 3D information model. Building data were introduced and updated into a 3D model that was then used to establish a 4D model based on the complete building database.

(2) Integrating 4D model technology for constructing a simulation of the building: The 4D draft simulation model allows users to review the planned status of a project in the context of a 3D model for any desired time. This allows project managers to check the integrity of the master schedule as well as highlights potential interface conflicts and logistical problems during the construction phase, supports the communication of product and process knowledge, and allows efficient tracking of work progress [9]. Applying the 4D model facilitates future replication and redesign of the open-building project. Furthermore, 4D model facilitates communications with subcontractors and improves project team collaboration.

(3) Estimating component schedule plan timing: Using the 4D model bar chart and work plan, engineering managers can estimate schedule plan timing related to component and material entrance control management, transportation, and manufacturing. Information also feeds back to the 
factory to facilitate the drafting and correction of the prefabrication schedule. Regular and real-time information exchanges between the factory and jobsite should reduce delay losses significantly.

\section{RFID-BIM APPLIED TO THE MEGA HOUSE OPEN-BUILDING DEVELOPMENT}

The project applied RFID-BIM to the five phases of (1) planning/design, (2) manufacturing, (3) construction, (4) maintenance and (5) recycle/reuse. RFID-BIM allowed the repetitive storage and retrieval of graphic and non-graphic data required at different phases for management purposes.

Figure 5 shows the information management framework model of the open-building life cycle.

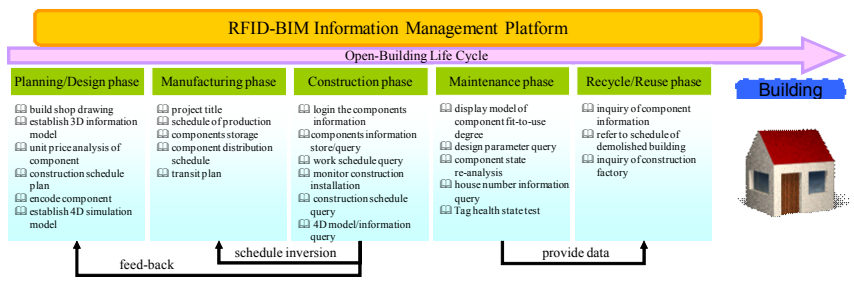

Fig.5 Information management framework model of openbuilding life cycle

\subsection{PLANNING AND DESIGN PHASE MANAGEMENT}

The planning and design of an open-building project reflects user expectations. The major purpose is to develop a 3D time factor integrated figure able to generate a $4 \mathrm{D}$ virtual reality model for construction progress simulation in the planning and design phase. During the design phase the structural components for prefabrication are analyzed and divided after completion of detailed design layout and structural analysis. According to the principles of the prefabricated element coding system, each prefabricated unit is assigned with a unique code stored on an RFID tag. Prefabricated component data is also stored in the 3D model for transmission to subsequent phases. This code that identifies the element is universally used in manufacturing, transport, storage, construction installation and recycling phases.

\subsection{MANUFACTURING PHASE MANAGEMENT}

Before beginning construction, managers must prepare the installation schedule according to the construction plan and develop a lifting schedule database. Relevant information on such is encoded onto prefabricated units. Structural components are manufactured according to a production schedule. Manufacturing and transportation schedules are reconfirmed based on the installation schedule and feed back to the manufacturer as a reference for planning and revising the production plan. The tag assigned for each element in the design phase is used to create shop drawings, production schedules, and inventory controls for the finished products in the storage yard. Figure 6 illustrates the open-building transportation schedule plan.

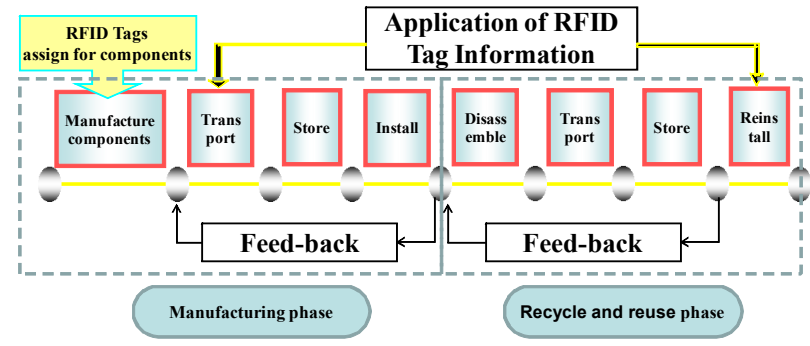

Fig.6 Open-building transportation schedule plan

\subsection{CONSTRUCTION PHASE MANAGEMENT}

Construction installation process simulation, schedule monitoring and control process based on BIM concept are applications that are integrated into the 4D model and associated resources (e.g., material and machine)for timely decision-making and project management purposes. A shift to ubiquitous computing is underway in construction management and surveillance applications. The framework model for construction installation schedule monitoring reflects installation process management needs (Fig. 7). The operational structure for construction scheduling control has two parts including:

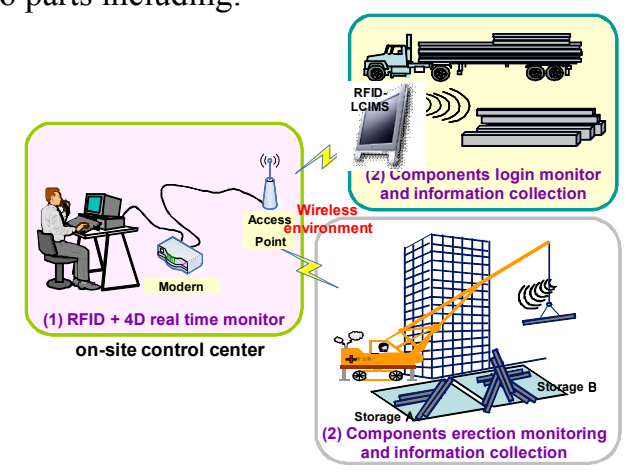

Fig.7 Framework model for construction installation schedule monitoring 
(1) RFID+4D real time monitor: 4D technology in building construction projects provides a CPM-based construction planning methodology that integrates 3D modeling functionality with time. When used to manage the integrated construction schedule, the $3 \mathrm{D}$ model refers to the architectural or structural model, time dimension refers to planned and actual schedules, and building unit information memory refers to RFID technology. Association of 3D model and schedule is thus the basis of 4D construction process simulation. Figure 8 shows the development framework model of an RFID+4D real time monitor.

This linkage supports an agile 4D model so that users can choose either the planned or actual schedule as their time dimension. Another advantage is that 4D management can generate both rough (e.g., sections-based) and detailed (e.g., activities-based) results. This paper visualizes the $4 \mathrm{D}$ model in a system platform and presents appropriate interfaces supporting their visualization and manipulation. Developing the RFID+4D model links components from the $3 \mathrm{D}$ model with construction activities, available resources, procurement restrictions and project schedules. The resulting 4D model allows project managers to display project development over time on a computer monitor. Such 4D software has the ability to start and stop the timeline as well as to directly jump to any date of interest. Additional information such as resources used or status can usually be displayed as well.

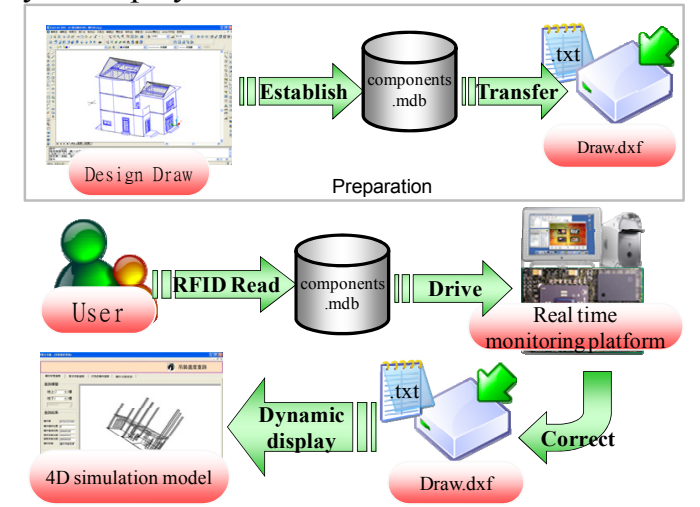

Fig. 8 The RFID + 4D real time monitor development framework model

(2) On-site control center: In line with distributed data collection and centralized management concepts, an on-site control center is established in the job office to collect and analyze construction information. When prefabricated element tag data is transmitted to the center it is imported into the system database for later inquiry and analysis. The control center runs Ultra Mobile PC (UMPC) for data write/read, data import/export, data query, and scheduling control. Through real time monitoring of the construction process, components scheduled for installation are repetitively tracked and well controlled to adhere to planned schedules.

\subsection{MAINTENANCE PHASE MANAGEMENT}

The maintenance phase represents the longest span in a building life cycle. The major application in this study uses RFID wireless transmission technology to link components information and history with the RFID-BIM platform database. It supports users to query building condition and effectively implement maintenance activities. This research supplies three service functions in this phase:

(1) Components physical condition queries: Improper usage or external factors during construction have the potential to influence component quality. Managers can research component physical condition to determine appropriate maintenance or replacement schedules. Each component is categorized as in one of three physical conditions, namely complete, worn and damaged. This function also provides manufacturer contact information for specialized checks.

(2) Component structural strength analyses: Over its useful life, a building may need to meet different user demands/requirements that require architectural additions, reconstruction work, interior decoration or relocation. Users can use the RFID reader to access essential information on the current condition of components.

(3) Tags state of health tests: Reader ability to read tag data is affected by the thickness of substrate material on component surfaces, component material texture and oxidation on the RFID tag. Users should regularly test the condition of tags during the maintenance phase to assess 
their current status and remaining useful life.

\subsection{RECYCLE AND REUSE PHASE MANAGEMENT}

RFID-supplied integrated open-building components information and the BIM-supplied simulated building model and construction process allow architects and engineers to conduct appropriate building redesign, recycling and reuse management work. Users can use the 4D simulation model of the installation process to optimize the building disassembly effort. Disassembly steps can be inferred from information stored on the RFID tags and integrated in the platform. Components may then be inspected to determine fitness for use in the subsequent life cycle. After redesign, component information and installation order will be applied to the new project.

\section{CONCLUSIONS AND FUTURE WORK}

This paper developed an automated information management platform to assist managers to manage building components throughout the open-building life cycle. The authors reviewed the open-building concept in the context of creating a flexible building construction environment. The open-building approach facilitates systematization of the construction environment by establishing a set of distinctly layered subsystems. The concept is applicable to the efficient regeneration of existing buildings. Utilizing RFID and BIM technology in the construction industry helps simplify the exchange of information and expertise between various parties during both the decision-making and constructive facility management phases. In the highlighted case study, the parametric model allowed a continuous updating of different suggestions in the planning and design phase in the areas of architectural design, construction planning and schedule planning. The comprehensive database provides drawings and numeric data necessary to determine quantities and sequence of building components relevant to the construction and maintenance phases and to implement building redesign work.

All participants in the building life cycle may use the RFID-BIM platform to search for critical building management information. Resources can be calculated automatically at any time point or period. Emerging advanced sensor and networking technology presents an opportunity for architects, engineers and owners to implement information automation and communication and significantly enhance the effectiveness of project task work.

\section{REFERENCES}

[1] Jaselskis, E. J., and El-Misalami, T. (2003) Implementing radio frequency identification in the construction process, Journal of Construction Engineering and Management, Vol.129, No.6 680-688.

[2] Jaselskis, E. J., Anderson, M. R., Jahren, C. T., Rodriguez, Y., and Njos,S. (1995) Radio-frequency identification applications in construction industry, Journal of Construction Engineering and Management, Vol.121, No.2 189-196.

[3] Yagi, J., Arai, E., and Arai, T. (2005) Parts and packets unification radio frequency identification (RFID) application for construction, Automation in Construction, Vol.14, No.4 477-490.

[4] Ernstrom, J.W. (2006). The contractors' guide to BIM, Associated General Contractors of America, Arlington, VA. [5] Smith, D. K., and Edgar, A. (2006). "Building information models."http://www.wbdg.org/design/bim.php (October 15, 2006).

[6] F.S. Liou, Keyless Data Acquisition in Construction. Archit. Sci. Rev. (1992) 9-16, USA.

[7] J.C. Whitaker, Radio Frequency Transmission Systems. Mc-Graw-Hill, New York, 1991.

[8] Clive Robinson, Structural BIM: discussion, case studies and latest developments, The Structural Design of Tall and Special Buildings Struct. Design Tall Spec. Build. $16,519-533$ (2007)

[9] Koo, B., Fischer, M. (2000). Feasibility Study of 4D CAD in CommercialConstruction. J. Constr. Engrg. andMgmt., Vol. 126, No. 4, pp. 251-260 